\title{
UNA APROXIMACIÓN A LA IDEA DE POLIS Y JUSTICIA EN HOMERO Y HESÍODO
}

\author{
Franko Benacchio \\ Universidad Adolfo Ibáñez. Santiago de Chile
}

\begin{abstract}
RESUMEN: Se propone una reflexión en torno a los orígenes homéricos y hesiódicos de la noción griega de Polis, especialmente en su relación con la idea

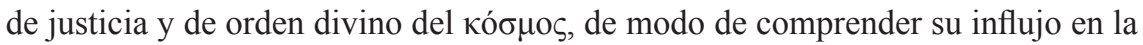
elaboración de las primeras organizaciones políticas que emergieron de las ruinas del mundo micénico.
\end{abstract}

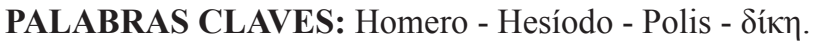

\section{AN APPROACH TO THE IDEA OF POLIS AND JUSTICE IN HOMER AND HESIOD}

\begin{abstract}
It is proposed a reflection on the homeric and hesiodic origins of the Greek notion of Polis, especially in its relation to the idea of justice and divine order of kosmos, in order to understand its influence in the elaboration of the first political organizations that emerged from the ruins of the Mycenaean world.
\end{abstract}

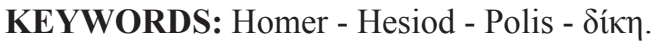

Recibido: 30.12.17 - Aceptado: 30.03.18

Correspondencia: Franko Benacchio S.

Email: frankobenacchio@hotmail.cl

Licenciado en Historia Univ. Gabriela Mistral.

Magister en Historia en Universidad Adolfo Ibáñez. 


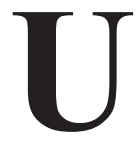

na de las creaciones más representativas de la antigua Hélade es, sin lugar a duda, aquella organización política, social, económica, religiosa y humana que denominaron con el término $\pi$ ó $\lambda$ ss. Este tipo de asociación humana connotaba para los antiguos griegos mucho más de lo que alude la mera traducción como "ciudadEstado", puesto que, en el seno de esta civilización, y especialmente en su época Clásica (siglos VI al IV), una Polis era concebida como mucho más de lo que abarcaba la simple extensión del espacio urbano habitado por una comunidad determinada, al cual solían denominar con el término de ö́ De tal suerte que la $\pi$ ó $\lambda ı \varsigma$ se extendía espacialmente más allá del recinto amurallado que delimitaba a la ǒ́ $\tau$, abarcando también el "campo" o $\chi \omega ́ \rho \alpha$.

No obstante, para los griegos de las épocas Arcaica y Clásica resultaba mucho más relevante que la extensión territorial de la Polis el elemento humano que la componía. En efecto, es notable a este respecto la definición que nos proporciona Aristóteles en el Libro I de su Política:

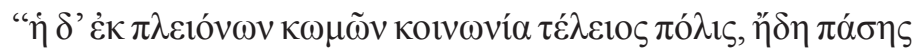

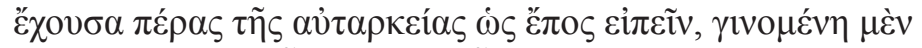

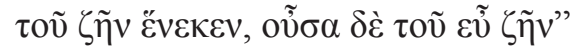

"La comunidad perfecta de varias aldeas es la ciudad, que tiene ya, por decirlo así, el nivel más elevado de autarquía, que surgió a causa de las necesidades de la vida, pero subsiste para la vida buena" ${ }^{1}$.

El propósito de la presente investigación es comprender los orígenes "ideológicos" de la noción de Polis que es posible colegir de la lectura de las dos fuentes más antiguas de la literatura helénica, vale decir, Homero y Hesíodo. En tal sentido, conviene dejar sentado desde ya que seguimos la línea interpretativa de J.M. Hurwit ${ }^{2}$, P. Debord ${ }^{3}$, S. Scully ${ }^{4}$, A.

1 Aristóteles, Política, I, 1252 b25.

2 Hurwit, JM. (1993), pp. 14-42.

3 Debord, P. (1973), pp. 225-240.

4 Scully, S. (1990), pp. 1-4. 
Domínguez Monedero 5 , entre otros, en el sentido de que consideramos que en Homero y Hesíodo encontramos sembradas buena parte de las "semillas ideológicas" que el espíritu griego irá desarrollando en su desenvolvimiento histórico. Es decir, concebimos los poemas homéricos y hesiódeos más que como alusivos a la época micénica, como testimonios del mundo en el que fueron compuestos, es decir, el siglo VIII, en el cual precisamente se iba perfilando lo que esencialmente sería Grecia durante las épocas Arcaica y Clásica, tal como sostiene Ileana Chirassi Colombo:

"El relato, el mito, repetido en la poesía Homérica y Hesiódica, iba más allá del servicio que prestaban a los grupos que pudieran utilizarlo como discurso caracterizante e identificador, superaba los límites del servicio a este o aquel génos y representaba un 'primer' discurso del mundo de las ciudades. Pero no lo hacía para perpetuar las modalidades de un poder tradicional (...) contra el cual se situaba, en principio teóricamente, el esfuerzo de la ciudad en tanto que espacio nuevo a repartir también de un modo nuevo" ${ }^{6}$.

Según esto, la poesía de Homero y Hesíodo, y especialmente la primera, no se limitan a establecer un "discurso ideológico" sobre el cual establecerían su dominio social y político las aristocracias que dominaron en casi todas las póleis a partir del siglo VIII, sino que más bien representan una concepción global de la vida en la Polis, abarcando prácticamente todos los aspectos que esta entrañaba en los albores del arcaísmo ${ }^{7}$. A este

5 Domínguez Monedero, A. (1993), pp. 36-37.

6 Chirassi Colombo, Ileana (2005), La religión griega. Dioses, héroes, ritos y misterios, Madrid, Alianza, p. 31.

7 Respecto del trasfondo cronológico de las tradiciones homéricas, Morris, I. (1986), pp. 81-138; y Hooker, J.T. (1989), pp. 79-90, establecen que todas ellas corresponden aproximadamente al siglo VIII, lo que coincide con la tradición historiográfica que sitúa la vida de Homero en este siglo crucial para la historia de Grecia. Morris considera que los relatos homéricos tienen como trasfondo el final de la así llamada "Edad Oscura", especialmente a partir de los atisbos de la organización humana que brindan (gran importancia del pastoreo y la agricultura como actividades de subsistencia, presencia de elementos artísticos que dan 
respecto, resulta notable el análisis que J.V. Luce realizó hace cuarenta años respecto del célebre pasaje del Libro XVIII de la Ilíada, en el cual el poeta describe con gran detalle las representaciones que el dios Hefesto repujó en la superficie externa del escudo de Aquiles. En esta línea, el autor llama la atención sobre la escena de un pleito en la denominada "ciudad en paz" señalando que:

"The issue is formally joined before an arbitrator, and then referred to the 'elders' for a verdict. On either interpretation we are given, I believe, a revealing glimpse of legal procedure in Homer's own day. The scene presents a stage in legal development, a stage intermediate between the blood-feudas a purely family matter, and the treatment of homicide as a crime punishable by the state". 8

Nos hallamos, pues, en presencia de un texto que, en el contexto de su carácter poético, transmite una noción de justicia que ha trascendido de la esfera privada al sometimiento al arbitraje de funcionarios del Estado encargados explícitamente de administrar justicia. Esto solo podía ser posible en el marco de una organización sociopolítica compleja, ya muy distante de la antigua organización característica del mundo micénico en la que el rey concentraba en su persona todo el poder político, judicial y religioso, en tanto sumo sacerdote de la comunidad. Ahora, en cambio, entre mediados y fines del siglo VIII, se ha consolidado una concepción política en la que el rey ( $\beta \alpha \sigma i \lambda \varepsilon v ́ \varsigma)$ ha sido despojado de buena parte de las funciones políticas que antaño desempeñaba el Fóv $\alpha \xi$ micénico ${ }^{9}$. Una

cuenta de una estabilidad comunitaria muy consolidada, etc.) Hooker, por su parte, se centra en el origen de esta tradición cultural que transmite Homero, concluyendo que ella se deriva de múltiples orígenes cronológicos y espaciales.

8 Luce, J.V. (1978), pp. 1-15. Por su parte, W. Jaeger considera que esta representación corresponde, en realidad, a una típica ciudad de Jonia en el siglo VIII, vid., Jaeger, W (1963), p. 104.

9 Jean Pierre Vernant ha sintetiza las repercusiones de este desarrollo del siguiente modo: "la desaparición del ánax parece haber dejado subsistir en forma simultánea las dos fuerzas sociales con las cuales habia tenido que transigir su poder: de una parte, las comunidades aldeas, de la otra, una aristocracia guerrera (...) Entre esas fuerzas opuestas, que pone en libertad 
de estas funciones más importantes que ya no desempeñarán los reyes dice relación con la administración de justicia, la cual, como parece indicar el pasaje del escudo de Aquiles, pasa a ser desempeñada por un "consejo de ancianos":

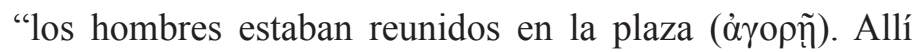

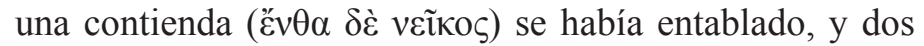
hombres pleiteaban por la pena debida a causa de un asesinato: uno insistía en que había pagado todo en su testimonio público, y el otro negaba haber recibido nada,

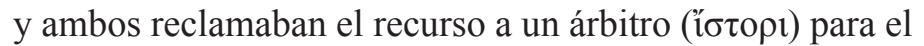
veredicto ( $\mu \eta \delta \dot{\varepsilon} v \dot{\varepsilon} \lambda \dot{\varepsilon} \sigma \theta \alpha \mathrm{l})$. Las gentes reclamaban a ambos, en defensa de uno o de otro, Y los heraldos intentaban contener al gentío. Los ancianos (oï $\delta \dot{\varepsilon} \gamma \varepsilon \dot{\varepsilon} \rho o v \tau \varepsilon \varsigma$ ) estaban sentados sobre pulidas piedras en círculo sagrado ( $\lambda i ́$ orcs

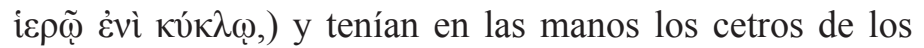
claros heraldos con los que se iban levantando para dar sus dictámenes por turno, en medio de ellos había dos talentos de oro en el suelo, para regalárselo al que pronunciara la

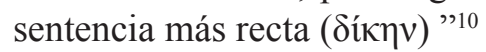

Como se ve, esta representación de un pleito en la "ciudad en paz" nos muestra claramente que esa "paz" no significaba ausencia total de problemas internos, sino que más bien implica la existencia de instituciones cuyo fin es precisamente canalizar esas divergencias, propias de toda convivencia humana. Además, el hecho de que esa institución corresponda a un colegio de jueces, demuestra que estamos en presencia de un nivel superior de organización política, en la cual la facultad jurisdiccional no es un atributo privativo de un determinado individuo, como parece haber

el hundimiento del sistema palatino y que en ocasiones van a enfrentarse con violencia, la búsqueda de un equilibrio un acuerdo, hará nacer, en un periodo de turbulencias, la reflexión moral y las especulaciones políticas que definirán una primera forma de 'sabiduría' humana (...) La imagen del rey, dueño y señor de todo poder, se reemplaza por la idea de funciones sociales especializadas, diferentes unas de otras y cuyo ajuste plantea dificiles problemas de equilibrio". Vernant, J.P. (1965), pp. 30-32.

10 Ilíada, XVIII, 497-508. 
sido el caso en las organizaciones políticas micénicas ${ }^{11}$. Según señalaba hace mucho tiempo Luigi Pareti, este contraste habría estado presente en el imaginario de los primeros rapsodas de la épica:

"Los rapsodas más antiguos de la Ilíada tenían todavía una idea bastante clara de lo que habían sido el rey y su poder en la época en que florecía todavía dicha institución, o sea, cuando aquél era todavía el sumo sacerdote, el árbitro supremo en las contiendas judiciales (...) Pero, por otra parte, la monarquía había ido decayendo (...) y el rey mismo había debido ceder parte de sus funciones a delegados (...)" ${ }^{12}$.

De esta manera, podemos concluir que la gestación de la Polis como fenómeno histórico tiene en Homero sus más profundas raíces, al trazar los poemas homéricos las principales líneas de delimitación de la voluntad individual con vistas a la construcción de una comunidad, a cuyas instituciones todos los miembros someten sus diferencias. Tal es la interpretación de Pierre Vidal-Naquet, a propósito de un conocido pasaje del Canto XV de la Ilíada, en el que Poseidón dialoga con Iris sobre la delimitación de los poderes entre los Crónidas ${ }^{13}$ :

11 Algunos autores, como H. Scholten (2004), pp. 335-357, A. Florez (2011), pp. 23-59 y C. Nagy (2003), p. 75, apuntan a las causas religiosas de este fenómeno, señalando que el distanciamiento de los dioses respecto de la esfera propiamente humana tendría como consecuencia el establecimiento de un nuevo orden institucional en el que la comunidad se daba a sí misma las instituciones fundamentales para garantizar la convivencia pacífica entre sus miembros. De aquí concluye Florez que la representación de esta ciudad, especialmente en la escena del conflicto en el ágora, corresponde a una noción fundamental de la Polis arcaica. Nótese también que, en otro pasaje, Homero acentúa la enorme importancia que reviste para la convivencia política el que quienes detentan la potestad jurisdiccional en la Polis (los ancianos o gerontes), se abstengan de dictar

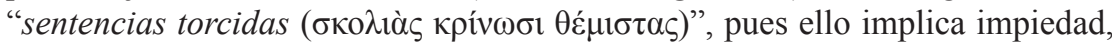

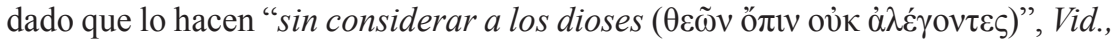
XVI, 384-388.

12 Pareti, L. (1961) Homero y la realidad histórica, México, Unión Tipográfica Editorial Hispanoamericana, pp. 55-56.

13 En el Canto XV, 187-193, Poseidón dice a Iris: 
"Este pasaje expresa tres ideas esenciales: la primera es la de echar suertes como medio para asignar las funciones, la segunda es la del dominio 'en común': la tierra y el monte Olimpo, morada de los dioses, no se encuentra bajo el dominio de Zeus. Se debe tener en cuenta a las demás potencias divinas (...) Estas tres ideas son constitutivas de la ciudad griega (...) La Ilíada es inconcebible sin cierta presencia de la ciudad (...) La ciudad de los dioses nos permite comprender cómo se había desarrollado la ciudad de los hombres en la época Arcaica (...) Los aqueos, como ejército de coalición, no constituyen una ciudad en el sentido clásico. No obstante, tienen dos instituciones esenciales: la asamblea de todos los combatientes (...) y el consejo, que convoca a los guerreros de mayor edad (...) Estas dos instituciones existen en el universo de los dioses (...) Por consiguiente, Homero presenta a las instituciones divinas a imagen de las humanas que él conoce (...) Resulta difícil determinar cuál era la estructura dominante: la ciudad, con los organismos de deliberación, o el oikos, es decir, la propiedad territorial en la que se asentaba el poder de los jefes de guerra"14.

Según esto, lo que encontramos en los poemas homéricos es, básicamente, el reflejo de un orden de relaciones ideales dentro de la comunidad política, cuyo fundamento último consiste en una noción de justicia que trasciende el ámbito meramente humano de la existencia, elevándose a la esfera divina, puesto que son los dioses, y muy especialmente Zeus, quienes resguardan el orden moral por sobre todas las instituciones que a sí mismos se dan los hombres. Así lo señala el mismo Homero en numerosos pasajes de la Ilíada, siendo uno de los más paradigmáticos de

"Tres somos los hijos de Crono a quienes Rea alumbró:

Zeus, yo, y el tercero Hades, soberano de los de bajo tierra.

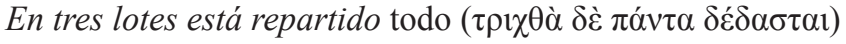

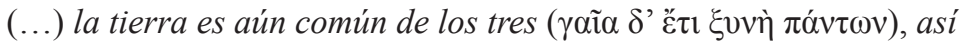
como también el gran Olimpo".

14 Vidal-Naquet, P (2007), El mundo de Homero, México, Fondo de Cultura Económica, pp. 58-59. 
los primeros aquel correspondiente al Canto XVI, ya citado más arriba, en el que se relaciona causalmente el advenimiento de desastres naturales con la injusticia, expresada en "sentencias torcidas".

Si bien esta noción de salvaguardia de la justicia por parte de los dioses es desarrollada posteriormente por Hesíodo, es importante destacar la conclusión de Ileana Chirassi Colombo:

"el discurso del mito que Homero y Hesíodo hilvanaron unitariamente describió un universo de dioses y de hombres comprometidos en una serie de relaciones, cuya textura se convirtió en el parámetro de comparación de la compleja red de relaciones internas que formaban la ciudad, y que ésta debía respetar, so pena de su propia anulación. Mito y religión eran esenciales para la ciudad"15.

¿Cuál era el contenido de esta noción de justicia que regía (o debía regir) las relaciones entre los hombres dentro de la Polis, y cuyos protectores eran los dioses? Para aproximarnos a este problema fundamental, Hesíodo se constituye en la principal referencia, no solo cronológica (puesto que es testigo privilegiado del surgimiento y consolidación de la Polis como entidad primordial del espíritu griego, en la Beocia del siglo VIII) ${ }^{16}$, sino también "sociológica", pues el poeta de Ascra se sitúa en el contexto de una transformación del sistema de organización social en el que la Polis como referente político comienza a desplazar progresivamente a la aldea ${ }^{17}$.

15 Chirassi Colombo, Iliana, Óp. Cit., p. 32.

16 Cfr. Gallego, J. (2017), La Polis griega. Orígenes, estructuras, enfoques, Buenos Aires, Editorial de la Facultad de Filosofía y Letras de la Universidad de Buenos Aires, pp. 117-175.

17 Si bien existe cierto consenso en la historiografía sobre el alto arcaísmo, en el sentido de que la obra hesiódica fundamental (los ”Е una transición más o menos clara entre los dos modos de resolver los conflictos propios del mundo campesino, vale decir, las instancias prejudiciales propias de la aldea, y el sometimiento a la jurisdicción de magistrados, que se constituyen en el ágora como definitorios de la Polis naciente, otros autores, como I. Morris (1994), passim, señalan que la disputa en el ágora que habrían protagonizado Hesíodo y su hermano Perses, correspondería más bien a una instancia aldeana, al igual que la escena representada en el "escudo de Aquiles" ya citada, puesto 
Pero antes de pasar a revisar algunos conceptos fundamentales sobre la justicia y su importancia social que Hesíodo establece en los "E $\rho \gamma \alpha \kappa \alpha i ̀ ~ ' H \mu \varepsilon ́ \rho \alpha 1$, consideramos necesario detenernos un momento en las ideas básicas que encontramos en ciertos pasajes de la Ilíada, de modo de apreciar hasta qué punto Homero influyó en Hesíodo, y dimensionar así cuál habría sido el aporte de cada uno de ellos a la elaboración de la noción primitiva de Polis.

Hemos dicho anteriormente que, en la época de Homero, ya estaríamos en presencia de la consolidación de una transformación sociopolítica, en el sentido de que el antiguo rey micénico (Fóv $\alpha \xi$ ) habría cedido gran parte de sus antiguas potestades a otras magistraturas, que surgirán progresivamente en las Polis que irán emergiendo de las ruinas de los antiguos palacios y templos micénicos ${ }^{18}$. No obstante, si bien en ciertos pasajes, como la célebre descripción del "escudo de Aquiles", en el Canto XVIII de la Ilíada, parece quedar de manifiesto que la principal facultad que el rey habría perdido en favor de los magistrados de la comunidad decía relación con la administración de justicia, en otros, por el contrario, observamos una notable concentración de los poderes en ciertos líderes de la confederación panaquea, específicamente en Agamenón ${ }^{19}$.

que los "ancianos" que se reunían en "circulo sagrado", escuchaban al pueblo, o "las gentes" como traducen algunos $(\lambda \alpha o i)$, que "aclamaban a ambos, en defensa

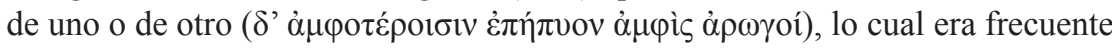
en el contexto aldeano prepolítico. Ilíada, XVIII, 502.

18 Vid., Vernant, J.P. (1969), Óp. Cit., pp. 29-37.

19 Podemos señalar, como ejemplos de esta concentración de poderes en el líder supremo, los versos 234-240 del Canto I de la Ilíada, donde Aquiles dice a Agamenón que el cetro ( $\sigma \kappa \tilde{\eta} \pi \tau \rho o v)$, que le otorgaba a él mismo el derecho a usar de la palabra en la asamblea, también simbolizaba que quienes lo portaban, los

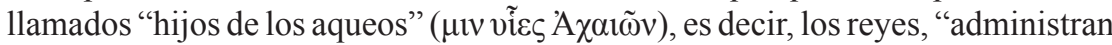
justicias" (

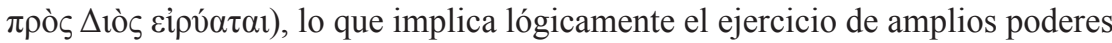
políticos y jurisdiccionales. Respecto de este trasfondo religioso de la autoridad detentada por los reyes, al concebírseles como garantes de las "leyes de Zeus", concordamos con W. Burkert, quien señala: "En particular, toda ley proviene de Zeus; los reyes que administra justicia reciben las ordenanzas 'de Zeus"'. Burkert, W. (2007), p. 177. 
Esta aparente contradicción entre concentración de poderes y surgimiento de magistraturas que pasaban a desempeñar ciertas prerrogativas que otrora eran definitorias de la realeza, es una de las claves del surgimiento de la Polis como organización político-comunitaria peculiar del mundo griego, puesto que entre ambos polos se irá tejiendo progresivamente el entramado "ideológico", en el que la vida en comunidad estará signada por la lucha ( $\dot{\alpha} \gamma \omega ́ v)$ entre diversos elementos heterogéneos, surgidos de la desaparición del mundo micénico, como señala J.P. Vernant:

"La desaparición del ánax (sic) parece haber dejado subsistir en forma simultánea las dos fuerzas sociales con las que había tenido que transigir su poder: de una parte, las comunidades aldeanas, $\mathrm{y}$, de otra, una aristocracia guerrera (...) Entre esas fuerzas opuestas que pone en libertad el hundimiento del sistema palatino, y que en ocasiones van a enfrentarse con violencia, la búsqueda de un equilibrio, de un acuerdo, hará nacer, en un período de turbulencias, la reflexión moral y las especulaciones políticas que definirán una primera forma de 'sabiduría' humana (...) La exaltación de los valores de lucha, de concurrencia, de rivalidad, se asocia al sentimiento de pertenencia a una sola y misma comunidad, a una exigencia de unidad y de unificación sociales. El espíritu de agón (sic) que anima a los genes nobiliarios, se manifiesta en todos los terrenos" ${ }^{\prime 20}$.

Es decir, según este autor, la unidad -acaso aparente- entre los diversos componentes nobiliarios y subalternos que el antiguo rey micénico garantizaba con su autoridad centralizada, se rompe definitivamente con su desaparición, dando lugar así a constantes luchas entre los elementos aristocráticos ( $\dot{\alpha} \gamma \omega v \alpha \imath)$. Estas luchas, paradójicamente, no conducen a la disgregación total de la comunidad, sino que, por el contrario, parecen haber consolidado la noción de pertenecía a un nuevo tipo de asociación, la $\pi$ ó $\lambda$ is. En esta asociación entre aristócratas que, de algún modo, "arrastran" a los grupos humanos que, por diversas razones, se encuentran bajo su dependencia $^{21}$, se irá configurando progresivamente un nuevo orden social,

20 Vernant, J.P., Óp. Cit., pp. 30, 35.

21 Cfr. Domínguez Monedero, A. (1993), pp. 66-95. 
político y económico, en el cual la estratificación social será un factor primordial que definirá al hombre que habita en ese espacio común como

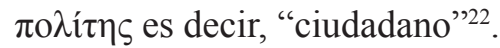

En este contexto de disputas internas en la naciente comunidad política, podemos situar la obra del beocio Hesíodo. En efecto, en sus

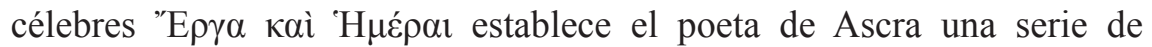
principios fundamentales que deben regir la conducta social del hombre.

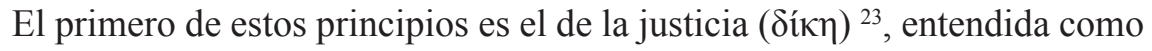
la sumisión a los designios de Zeus, quien la ha establecido como guía y directriz de la convivencia entre ellos, tal como señala Hesíodo:

"Esta ley impuso a los hombres el Cronión: a los peces, fieras y aves voladoras, comerse los unos a los otros ( $\varepsilon^{\circ} \sigma \theta \varepsilon v$

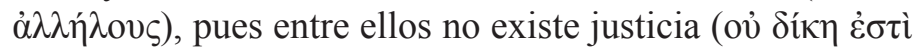
$\mu \varepsilon \tau^{\prime} \alpha$ v่oĩs). A los hombres, en cambio, les dio la justicia

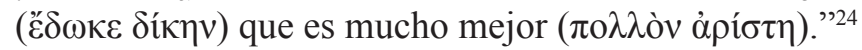

Es decir, a su entender, la justicia es entendida esencialmente en clave divina, siendo así considerada como una condición propia y definitoria del hombre, que lo diferencia sustancialmente del animal irracional, pero que, al propio tiempo, lo trasciende, en tanto no es concebida como creación

22 Algunos autores han establecido, ya en Homero, ciertas distinciones sociales que podrían interpretarse como reflejo de la evolución posterior de este concepto de pertenencia a la comunidad cívica. Tal es el caso de Holoka J.P. (1990) p. 393-461, y Andreev, J.V. (1988), pp. 5-65. Holoka, en particular, señala el caso del Canto II de la Ilíada, en el cual se narra la disputa entre Tersites y los líderes de la coalición aquea con motivo de la asamblea que convocara Odiseo para discutir sobre la continuidad de la empresa. Quizá sea una interesante prueba de esta dependencia de los ciudadanos de diversa condición social respecto de la comunidad cívica, aunque pertenezca a una época muy posterior dentro del arcaísmo, la Máxima XII (D.) del poeta Focílides de Mileto: "Muchas ventajas

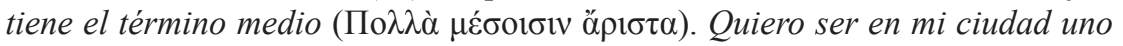

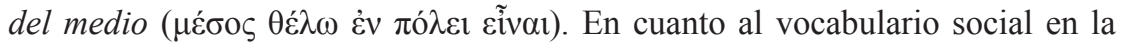
épica griega, Vid., Donlan, W. (1978), pp. 95-111; Lévy, E. (1989), pp. 123-131.

23 Cfr., sobre la concepción de justicia en Hesíodo, Beal, E.F. (2005-2006), pp. 161-182.

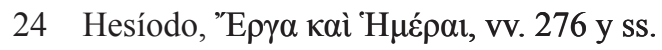


humana, sino como un don de Zeus, el dios supremo que rige el mundo desde que destronara a su padre Crono. Esto le confiere a la justicia un carácter divino que lleva a Hesíodo a considerarla como una diosa, hija de Zeus ${ }^{25}$. Pero esta justicia no solo debe regir la convivencia entre los miembros de la comunidad (en este caso la aldea beocia de Ascra, en cuyo seno se produce la disputa entre Hesíodo y su hermano Perses, leitmotiv del poema), sino que también debe ser una advertencia para quienes están en posición de autoridad sobre sus semejantes, en el sentido de que es el mismo Zeus que la ha establecido como directriz de la conducta humana el que se constituye en garante de su cumplimiento ${ }^{26}$. Es en este sentido en el que Stephanie Nelson establece una nueva interpretación de la fábula hesiódica del halcón y el ruiseñor:

"There is a third possibility. Both readings may be intended. If so, Hesiod has led us to believe that the helpless victim in the hands of a greater power is himself, only to make us realize, finally, that not he, but the giftgobbling kings, are subject to a force that reduces their mighty words to meaningless twittering" 27 .

Consideramos que esta interpretación de la narración de Hesíodo se corresponde con el mensaje general que transmite la obra. Pues parece evidente que Hesíodo no pretende agotar su discurso en una mera advertencia

25 Para un análisis bastante acucioso del carácter religioso de la concepción social de Hesíodo, puede ser de utilidad consultar a Burkert, W. (2007), pp. 173; 330 y ss.

26 “Cuando la Diké es violada ( $\tau \tilde{\eta} \varsigma \delta \grave{\varepsilon} \Delta$ íkn

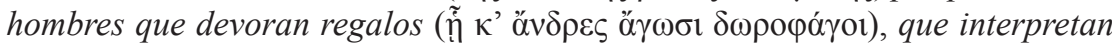

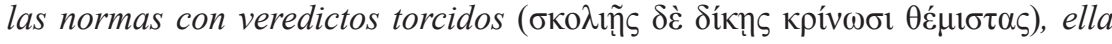
$v a$ detrás quejándose de la ciudad y de las costumbres de las gentes ( $\pi$ ó $\lambda \mathrm{v}$

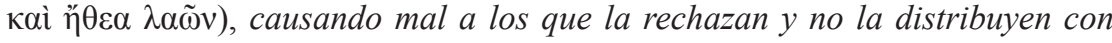

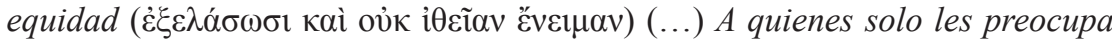

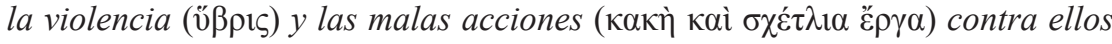

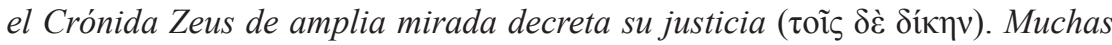
veces toda una ciudad carga con la culpa de un solo hombre malvado ( $\pi \mathrm{0} \lambda \lambda \alpha$ áк1

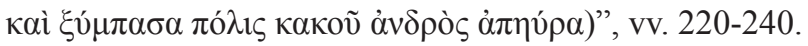

27 Nelson, S. (1997), pp. 235-247. 
a Perses, sugiriéndole que no confíe en las instancias judiciales humanas, (las cuales lo han favorecido en el pleito, aun cuando él aspira a obtener una porción mayor que la de su hermano), aconsejándole asimismo que más justo es trabajar que confiar en esas instancias, pues Zeus ha impuesto a los hombres el trabajo, sino que va más allá en su planteamiento, cuya conclusión parece ser el imperio de Zeus sobre todos los hombres, incluso los reyes, los cuales on responsables, en última instancia, de los decretos que emiten: todo decreto trae una consecuencia; si es justo, al bendición de los dioses; si es malo, la destrucción de la ciudad ${ }^{28}$. Así, Hesíodo establece una limitación divina al poder de los reyes que va configurando el marco de delimitación de la vida humana en sociedad, en aquella estructura política que comenzaba a consolidarse, vale decir, la Polis, que se constituye así en el sustrato básico de la cultura griega.

\section{Referencias Bibliográficas}

ANDREEV, J. V. (1988). "Die homerische Gesellschaft", Klio: Beiträge zur alten Geschichte, 70. Pp. 5-65.

BEAL, E.F. (2005-2006). "Tratise on Justice: "Works and Days" 109-380,". The Classical Journal, Vol. 110, n. 2. Pp. 161-182.

BLICKMAN, D.R. (1987). "Styx and the Justice of Zeus in Hesiod's "Theogony",. Phoenix, Vol. 41, No. 4. Pp. 341-355.

BURKERT, W. (2007). Religión griega. Arcaica y clásica. Abada: Madrid.

CHRIASSI COLOMBO, I. (2005). La religión griega. Dioses, héroes, ritos y misterios. Alianza: Madrid.

DEBORD, P. (1973). "Esclavage mycénien, D homérique”. Revue des Études Anciennes, 75, 3. Pp. 225-240.

DONLAN, W. (1978). "Social Vocabulary and Its Relationship to Political Propaganda in Fifth-Century Athens". Quaderni Urbinati di Cultura Classica, No. 27. Pp. 95-111.

DOMÍNGUEZ MONEDERO, A. (1993). La Polis y la expansión colonial griega. Siglos VIII-VI. Síntesis: Madrid.

FLOREZ, A. (2011). "Kosmos y Polis en el Escudo de Aquiles". Universitas Philosophica, 56, año 28. Pp. 23-59.

GALlEGO, J. (2017). La Polis griega. Orígenes, estructuras, enfoques. Editorial de la Facultad de Filosofía y Letras de la Universidad de Buenos Aires: Buenos Aires.

28 Cfr., vv. 246-247; 267-269. Sobre esto, cfr.., Burkert, W, Óp. Cit., p. 330; Blickman, D.R. (1987), pp. 341-355. 
HOOKER, J.T. (1989). "Gift in Homer". Bulletin of the Institute of Classical Studies, 36. Pp. 79-90.

HOLOKA, J.P. (1990). "Homer Studies, 1978-1983" (I). The Classical World Vol. 84, No. 2. Pp. 393-461.

HURWIT, J.M. (1993). "Art, Poetry and the Polis in Age of Homer". From Pasture to Polis: Art in the Age of Homer. University of Missouri Press: Columbia.

JAEGER, W. (1962). Paideia: los ideales de la cultura griega. FCE: México.

LÉVY, E. (1989). "De quelques allusions à l'Iliade dans l'Odyssée". Maison de l'Orient et de la Méditerranée, 19,1. Pp. 123-131.

LUCE, J.V. (1978). "The "Polis" in Homer and Hesiod". Proceedings of the Royal Irish Academy: Archaeology, Culture, History, Literature, Vol. 78. Pp. $1-15$.

MORRIS, I. (1986). "The Use and Abuse of Homer". Classical Antiquity, Vol. 5, No. 1. Pp. 81-138.

--- (1994). "Village society and the rise of the Greek state", en Doukellis. P.N. y L. G. Mendoni (eds,). Structures rurales et sociétés antiques. Pp. 49-53. Annales Littéraires de l'Université de Besançon: París.

NAGY, G. (1997). "The Shield of Achilles: Ends of the Iliad and Beginnings of the Polis", en Langdon, S. (ed.), New Light on a Dark Age: Exploring the Culture of Geometric Greece. University of Missouri Press: Columbia. Pp. 72-87.

NELSON, S. (1997). "The Justice of Zeus in Hesiod's Fable of the Hawk and the Nightingale". The Classical Journal, Vol. 92, No. 3. PP. 235-247.

PARETI, L. (1961). Homero y la realidad histórica. Unión Tipográfica Editorial Hispanoamericana: México.

SCULY, S. (1990). Homer and the Sacred City. Cornell University Press: Nueva York.

SHERRATT, E.S. (1990). “'Reading the texts': archaeology and the Homeric question". Antiquity, 64. Pp. 807-824.

SCHOLTEN, H. (2004). "Die Schildbeschreibung Homers als Spiegel der frühgriechischen Staatswerdung". Gymnasium, 111, 4. Pp. 335-357.

VERNANT, J.P. (1965). Los orígenes del pensamiento griego. Editorial Universitaria de Buenos Aires: Buenos Aires.

VIDAL-NAQUET, P. (2007). El mundo de Homero. Fondo de Cultura Económica: México. 